\title{
Caudal Epidural Steroid Application at Chronic Low Back and Leg Pain: Experience of Fifty Cases and the Analysis of Pain and Satisfaction of the Cases
}

\author{
Ibrahim Burak Atci ${ }^{\mathrm{a}, \mathrm{b}}$, Serdal Albayrak ${ }^{\mathrm{a}}$, Emre Durdaga ${ }^{\mathrm{a}}$, Omer Ayden ${ }^{\mathrm{a}}$
}

\begin{abstract}
Background: In this article, we present the results of 50 patients whom we treated with epidural steroid injection, and our experience on the subject.

Methods: Fifty patients who were followed in our clinic between January 2011 and August 2011 were assessed retrospectively. These were the patients who had chronic low back and leg pain due to lomber spinal degeneration and for whom operation was not recommended and lomber caudal epidural steroid was applied.
\end{abstract}

Results: In our study, 50 patients having low back pain or leg pain or low back and leg pain together were assessed, and regression at rVAS score of $86 \%$ of the patients was detected for a short period after the intervention. VAS scores of $14 \%$ of the patients were not different. On long-term follow-up rVAS score analysis of the patients showed regression at $74 \%$ of the cases.

Conclusion: Caudal steroid injection is a safe and efficient treatment method for the patients who have radicular pain, who do not respond to conservative treatment and for whom surgery is not recommended. Randomized double blind studies are needed to assess its superiority to other conservative methods.

Keywords: Chronic low back pain; Lomber epidural steroid applications; Chronic radicular pain

\section{Introduction}

Chronic low back pain, which has negative effects on life and

Manuscript accepted for publication October 15, 2013

a Department of Neurosurgery, Elazig Training and Research Hospital, Hospital Street Rizaiye Road, 23100 Elazig, Turkey

${ }^{\mathrm{b}}$ Corresponding author: Ibrahim Burak Atci, Department of

Neurosurgery, Elazig Training and Research Hospital, Hospital Street

Rizaiye Road, 23100 Elazig, Turkey. Email: drburakatci@hotmail.com

doi: http://dx.doi.org/10.4021/jnr212w which causes labor force loss, is an important community health problem. According to the data, $10 \%$ of all low back pains continue for $4-6$ weeks, and are then called chronic low back pain. The treatment of chronic axial and/or radicular low back pain, which is the most frequently encountered complaint in general neurosurgery practice, includes a wide range of options. Lomber epidural steroid applications and surgical methods can be used when the conservative methods are inadequate [1].

Today, it is stated that inflammatory process in addition to mechanical compression plays an important role in the formation of pain especially related to discopathy $[2,3]$. Nowadays, by the development of imaging quality of radiologic survey and these methods being attainable, lomber degenerative diseases are diagnosed before the formation of a serious neural compression. For these patients, lomber steroid applications can be used to suppress inflammation and this allows the patient to continue the former daily activities in the early period $[4,5]$.

In this retrospective study, we present our 50 case experience related to lomber caudal steroid injections which is one of the safest methods of lomber epidural steroid applications.

\section{Patients and Method}

Fifty patients who were followed in our clinic between January 2011 and August 2011 were assessed retrospectively. These were the patients who had chronic low back and leg pain due to lomber spinal degeneration and for whom operation was not recommended and lomber caudal epidural steroid was applied.

They had low back pain for at least 3 months at the time of assessment, they had radicular symptoms at examination, they did not respond to medical treatment and physical therapy, they had magnetic resonance imaging (MRI) findings consistent to their clinical condition and they were not recommended surgery. Common surgical indications defined by the authors at chronic low back pain were spinal instability, progressive neurologic deficit, findings of conus medullaris cauda equina, neurologic claudicatio, and severe pain which 
Table 1. Common Surgical Indications Defined by the Authors at Chronic Low Back Pain

\author{
Common Surgical Indications \\ Spinal instability \\ Neurologic deficit \\ Signs of conus medullaris, cauda equina \\ Neurologic claudication \\ Intractable pain, resistant to conventional therapies
}

affects daily activities negatively (Table 1).

Patients were hospitalized and blood parameters were studied. The patients were told about the procedure and their written consents were taken before the operation. In the operating room, intravenous access was provided firstly. The patients were at prone position with a pillow under the inguinal part to support the position. Sacral hiatus was palpated. Local anesthesia was provided by the injection of lidocaine to the operation site, and $22 \mathrm{G}$ peripheral nerve blockade needle was preceded into the hiatus by a $45^{\circ}$ angle. Reaching the bone structure, the angle was decreased to $10^{\circ}$, and by proceeding approximately $5 \mathrm{~cm}$, hiatus was entered and epidural region was attained.

Being maximum $20 \mathrm{~mL}$, triamcinolone, prilocaine and bupivacain $(80 \mathrm{mg}$ triamcinolone $+40 \mathrm{mg}$ prilocaine $+15 \mathrm{mg}$ bupivacain $+13 \mathrm{~mL} 0.9 \% \mathrm{NaCl}$ ) were administered. After the injection, the patients were mobilized by following their vital signs, neurologic examination and complaints closely. After the intervention, salt free diet was recommended for 10 days. Physical therapy program was not applied. For the assessment of pain of the patients, visual analog scale (VAS, $0-10$ ) was used for both low back and radicular pain. Besides, the patients were assessed by straight leg rising (SLR) degree, hand finger-floor distance (HFFD) (as cm, approximating the hand fingers to foot fingers when the patient is standing, two legs being next to each other, bending forward from waist without folding the knees), and patient satisfaction scale (very bad $=0$, bad $=1, \operatorname{good}=2$, very $\operatorname{good}=3$, perfect $=4$ ). At least $50 \%$ decrease of pain and at least 2 of patient satisfaction scale after the treatment are accepted as success. Follow-up of all the patients after the operation was scheduled at 1, 3 and 6 months.

\section{Results}

Ages of the patients were between 22 and 73 . Twenty-two of them $(44 \%)$ were men and $28(48 \%)$ were women. Pain expanded to right leg at $11(22 \%)$ of the patients, to left leg at $16(32 \%)$ of the patients, and to both legs at $5(10 \%)$ of the patients; $18(36 \%)$ of the patients did not have leg pain, but they had severe low back pain. Besides, there were sensorial deficit at $13(26 \%)$ of the patients who did not have motor deficit. As for the localization of disc herniation, it was at L4-5 level at $26(52 \%)$ of the patients (Table 2), and 43 $(86 \%)$ of the patients benefited from the operation. The other 7 (14\%) patients were followed (Table 2).

Mean radicular VAS (rVAS) values of the patients before the intervention were $7.97 \pm 1.12$, and it was $3.33 \pm$ 1.30 at the end of the first month, $3.24 \pm 1.72$ at the end of the third month and $4.96 \pm 1.6$ at the end of the sixth month. When compared to the rVAS values before the treatment, the result was statistically significant $(\mathrm{P}<0.05)$. VAS values on the sixth month were higher than the previous controls, but the difference was not found to be statistically significant $(\mathrm{P}$ $>0.05$ ) (Fig. 1).

Table 2. Summary of MRI Findings in Patients

26 patients with L4-5

19 patients with L5-S1

5 patients with L3-4
21 patients with lumbar midline or paramedian protrusion, or bulging

15 patients with lumbar midline or paramedian protrusion, or bulging

3 patients with lumbar midline or paramedian protrusion, or bulging
5 patients with lumbar foraminal stenosis

4 patients with lumbar foraminal stenosis

5 patients with lumbar foraminal stenosis 


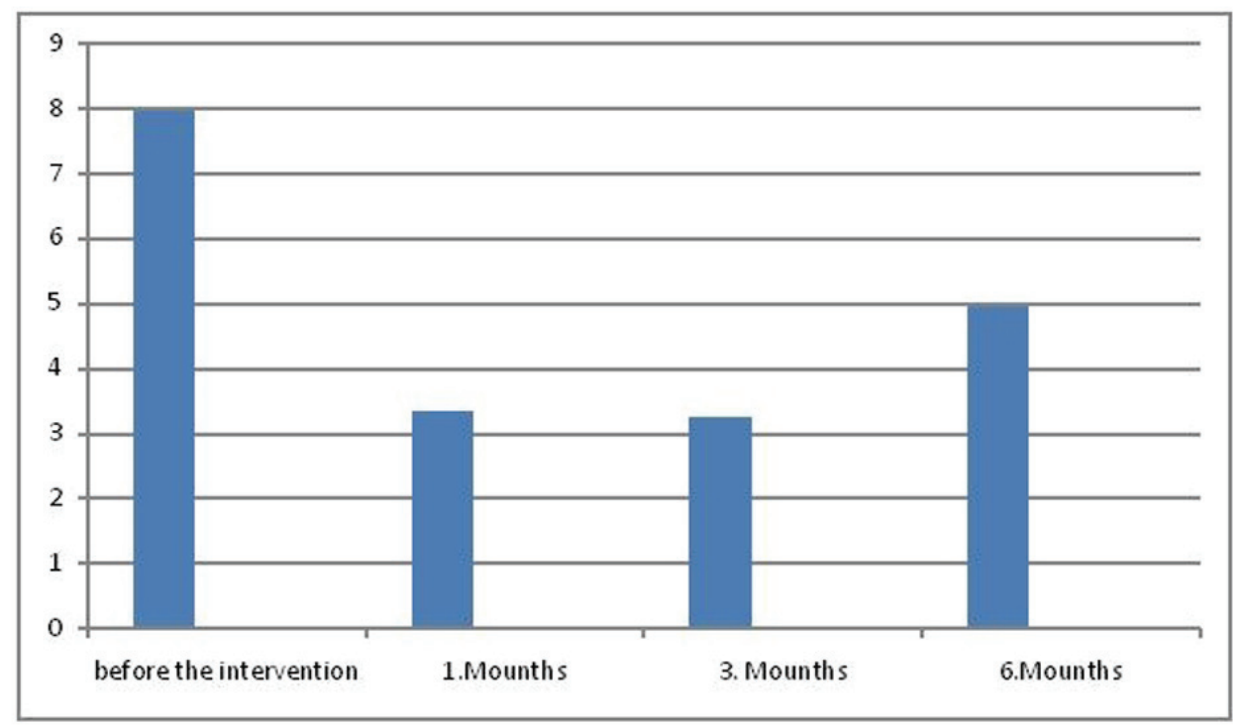

Figure 1. rVAS (mean radicular VAS).

Low back pain VAS (bVAS) values of the patients before the intervention were $7.62 \pm 1.12$, it was $4.44 \pm 1.25$ at the end of the first month, $5.26 \pm 1.32$ at the end of the third month and $6.02 \pm 1.5$ at the end of the sixth month. When compared to the bVAS values before the treatment, it was found that the healing was statistically significant at the end of the first month $(\mathrm{P}<0.05)$. However, increasing bVAS values at third and sixth month follow-up when compared to the first control, showed that the healing was not statistically significant $(\mathrm{P}>0.05)$ (Fig. 2).

Mean straight leg rising degree was $47.82 \pm 11.20$ before the intervention. On follow-up, it was found to be $61.44 \pm$
12.20 at the end of the first month, $72.76 \pm 11.23$ at the end of the third month and $74.60 \pm 14.55^{\circ}$ at the end of the sixth month. The improvement of straight leg rising degree on follow-up when compared to admission values was statistically significant $(\mathrm{P}<0.05)$ (Fig. 3).

Hand finger-floor distance was $39 \pm 2.3 \mathrm{~cm}$ before the intervention, and it was $32 \pm 1.2 \mathrm{~cm}$ at the first month, 19 $\pm 1.8 \mathrm{~cm}$ at the third month and $21 \pm 3.2 \mathrm{~cm}$ at the end of the sixth month. The difference between the initial values and the first, third and sixth month values was statistically significant $(\mathrm{P}<0.05)$ (Fig. 4).

Patient satisfaction scale at the sixth month after the in-

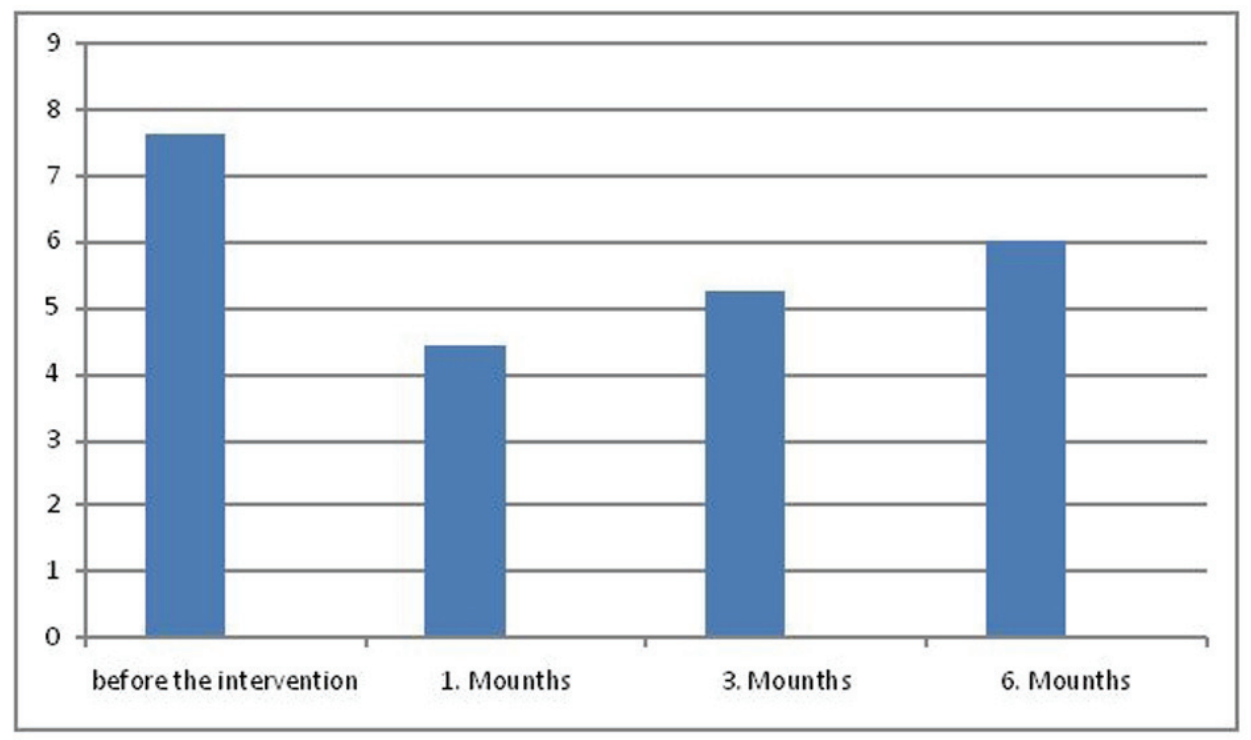

Figure 2. bVAS (low back pain VAS). 


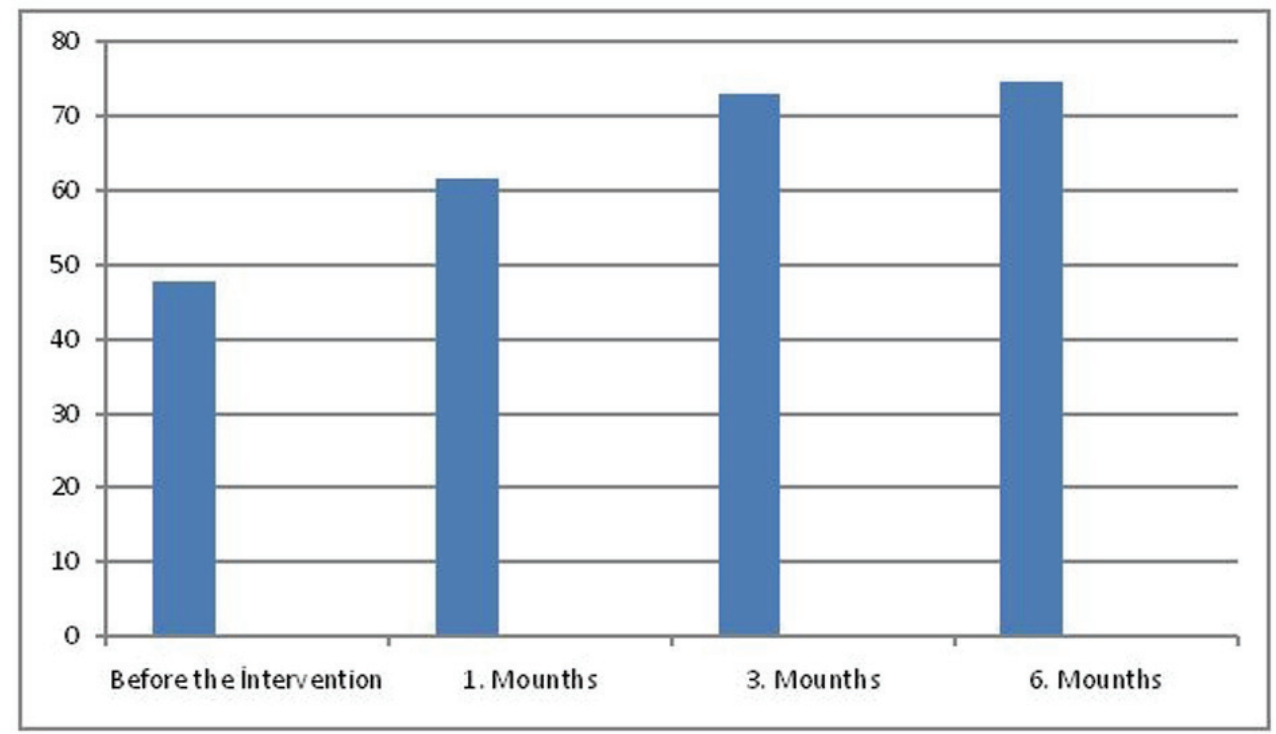

Figure 3. SLR (mean straight leg rising).

tervention was defined as 0 at $5 \%$ of the patients, 1 at $17 \%, 2$ at $6 \%, 3$ at $56 \%, 4$ at $16 \%$ of the patients, and the difference was found to be statistically significant $(\mathrm{P}<0.05)$.

As for the side effects due to the intervention, 4 (8\%) of the patients had temporary hypotension, and transient paresthesia occurred in 7 patients. There was not any important complication.

\section{Discussion}

The first epidural drug application was performed at 1885 by James Coming who had applied epidural cocaine through T11-T12 distance. Sicard, Cathalin and Roberci had improved epidural interventions afterwards [5]. Epidural steroid applications have been started since 1950's, caudal and interlaminar intervention was defined in 1960's and transforaminal intervention was defined in 1970's [2, 6]. Thereafter fluoroscopic control was added to these methods, and higher treatment success was achieved with lower dosage [1, 7-10].

Other than neural mechanical compression, anulus rupture and contact of the disc content to the epidural space and following dissemination of inflammatory enzyme and cytocines such as matrix nitric oxide, metalloproteinase, prosta-

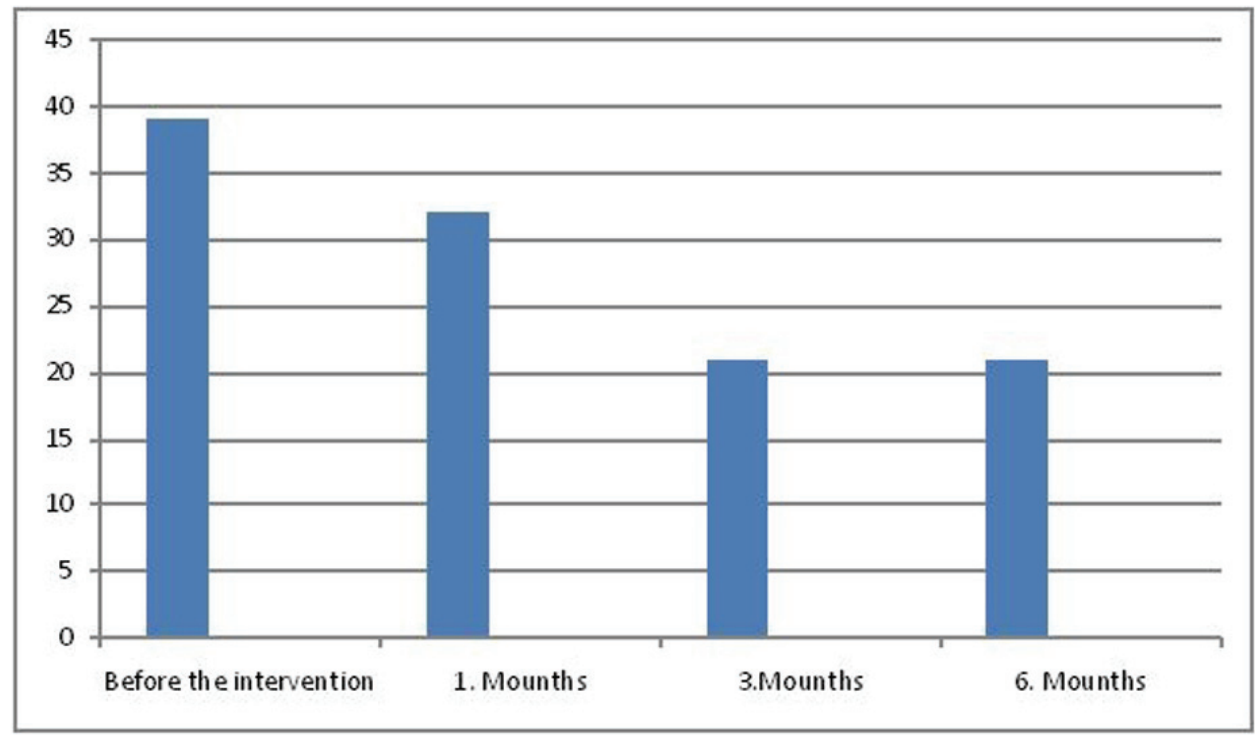

Figure 4. Hand finger-floor distance. 
glandin E, IL-6 and TNF-alpha also play an important role in the formation of discogenic pain $[2,3,5]$.

The efficiency of epidural steroid applications is related to breaking this inflammation cascade and concurrently adhesion and fibrosis is also suppressed [5].

Steroid could be applied by caudal route, transforaminal route or translaminar route into the epidural space. Although there are advantages of the techniques to each other, caudal steroid injection is preferred by the clinicians [4]. Lomber caudal steroid injection is superior to other methods as it is safe, it is effective on caudal lomber spine which is much more affected at lomber degenerative disease, it affects several roots, and as it is easy to reach ventral epidural space by injection [4, 11]. By this easily applied method, much knowledge is obtained on epidural steroid applications. Manchikanti et al found lomber caudal steroid injections efficient by their randomized controlled study on patients with lomber spinal stenosis [12]. In a study of the same authors on lomber disc patients complaining radiculopathy, local anesthetics were found to be effective on pain control when applied with steroid or itself alone, but steroid application was found to have positive effects on long-term follow-up [13]. Favorable results were obtained on two other studies in which caudal steroid injection was applied and radicular pain was assessed $[12,14]$.

In a systematic review of Parr et al, articles related to caudal steroid injection in between 1966 and 2011 were inspected, and efficiency was denoted at chronic axial or discogenic pain, radiculopathy and pain following lomber surgery [4]. In a review inspecting efficiency of caudal steroid injection on low back and leg pain, injections were found to be effective at radicular pain but no effect was detected on axial pain [5].

In our study, 50 patients having low back pain or leg pain or low back and leg pain together were assessed; regression at rVAS score of $86 \%$ of the patients was detected for a short period after the intervention. VAS scores of $14 \%$ of the patients were not different. On long-term follow-up rVAS score analysis of the patients showed regression at $74 \%$ of the cases.

In our study when radicular low back pain was inspected statistically, caudal steroid injection was found to be effective on short- and long-term follow-up, correlated to the literature. However while the statistical study assessing low back pain showed good results on short term, the efficiency decreased afterwards. Although most of the studies on this subject state that the caudal injections are effective on both complaints, our study supports this hypothesis partially. It is considered that the effect of the steroid injection is to suppress inflammation. Although the caudal injection eliminates the cytocines in the epidural space, it cannot ameliorate the degeneration of the disc as the source of pain. Therefore its efficiency in axial pain is limited. Partly corresponding to the literature, we also concluded that, steroid application in caudal axial low back pain is insufficient.

When SLR degrees and HFFD measurements are considered in our study, it is encountered that SLR degrees increased and HFFD measurements decreased. This depicts that epidural steroid application also leads to functional amelioration of patients.

According to our opinion, although there are some similar articles in which patient follow-up is carried out by VAS score [10], the most important limitation of our study is that, functionality could not be evaluated by the scales such as Oswersy, SF-36 during assessment and follow-up of the patients. Although the authors used these scales to evaluate the functionality of these patients in the first set-up of the study, they could not obtain the suitable data on this issue. The basic reason of this is that the socioeconomic level of the patient population of the hospital in which the study has been conducted was not sufficient for the survey, and the other reason was language problem between doctor and the patient. Therefore they followed the patient by more simple and understandable parameters.

Low back pain is frequently seen in population. When it is assessed with radiculopathy, surgery is needed for $10-15 \%$ of the cases $[2,15]$. Other patients are followed up by conservative treatment. Lately, spinal injections are also important in the management of chronic low back pain. However the cases must be selected correctly. It must be understood that spinal steroid injection cannot be alternative to surgery. Nevertheless, it must be noticed that application of the conservative methods on the patients for whom surgery is not recommended, is not possible all the time. Some of our patients are not able to rest enough and benefit from physical therapy because of their heavy work. Social circumstances of these patients lead the physician to choose a fast and safe treatment method. In this aspect, caudal spinal epidural injection can be helpful. However, our opinion is that it must be planned following or accompanying other conservative methods for maximum efficiency of the treatment.

\section{Conclusion}

Caudal steroid injection is a safe and efficient treatment method for the patients who have radicular pain, who do not respond to conservative treatment and for whom surgery is not recommended. Randomized double blind studies are needed to assess its superiority to other conservative methods.

\section{References}

1. Benyamin RM, Manchikanti L, Parr AT, Diwan S, Singh V, Falco FJ, Datta S, et al. The effectiveness of lumbar interlaminar epidural injections in managing chronic low back and lower extremity pain. Pain Physician. 
2012;15(4):E363-404.

2. Goupille P, Jayson MI, Valat JP, Freemont AJ. The role of inflammation in disk herniation-associated radiculopathy. Semin Arthritis Rheum. 1998;28(1):60-71.

3. Hamamoto H, Miyamoto H, Doita M, Takada T, Nishida K, Kurosaka M. Capability of nondegenerated and degenerated discs in producing inflammatory agents with or without macrophage interaction. Spine (Phila $\mathrm{Pa}$ 1976). 2012;37(3):161-167.

4. Parr AT, Manchikanti L, Hameed H, Conn A, Manchikanti KN, Benyamin RM, Diwan S, et al. Caudal epidural injections in the management of chronic low back pain: a systematic appraisal of the literature. Pain Physician. 2012;15(3):E159-198.

5. Stout A. Epidural steroid injections for low back pain. Phys Med Rehabil Clin N Am. 2010;21(4):825-834.

6. Benzon HT. Epidural steroid injections for low back pain and lumbosacral radiculopathy. Pain. 1986;24(3):277295.

7. Bogduk N, Aprill C, Derby R. Epidural steroids injections. In: White AH, Schofferman J, eds. Spine Care, Diagnosis, and Treatment. St. Louis: Mosby, 1995:322343.

8. Buchner M, Zeifang F, Brocai DR, Schiltenwolf M. Epidural corticosteroid injection in the conservative management of sciatica. Clin Orthop Relat Res. 2000;(375):149-156.

9. Lievre JA, Bloch-Michel H, Attali P. [Epidural hydrocortisone in the treatment of sciatica]. Rev Rhum Mal
Osteoartic. 1955;22(9-10):696-697.

10. Botwin KP, Gruber RD, Bouchlas CG, Torres-Ramos FM, Sanelli JT, Freeman ED, Slaten WK, et al. Fluoroscopically guided lumbar transformational epidural steroid injections in degenerative lumbar stenosis: an outcome study. Am J Phys Med Rehabil. 2002;81(12):898-905.

11. Manchikanti L, Cash KA, McManus CD, Pampati V, Fellows B. Results of 2-year follow-up of a randomized, double-blind, controlled trial of fluoroscopic caudal epidural injections in central spinal stenosis. Pain Physician. 2012;15(5):371-384.

12. Rabinovitch DL, Peliowski A, Furlan AD. Influence of lumbar epidural injection volume on pain relief for radicular leg pain and/or low back pain. Spine J. 2009;9(6):509-517.

13. Manchikanti L, Singh V, Cash KA, Pampati V, Damron KS, Boswell MV. Effect of fluoroscopically guided caudal epidural steroid or local anesthetic injections in the treatment of lumbar disc herniation and radiculitis: a randomized, controlled, double blind trial with a twoyear follow-up. Pain Physician. 2012;15(4):273-286.

14. Singh H, Kaur M, Nagpal S, Gupta S. Role of caudal epidural steroid injections in lumbar disc prolapse. J Indian Med Assoc. 2010;108(5):287-288, 290-281.

15. Bush K, Cowan N, Katz DE, Gishen P. The natural history of sciatica associated with disc pathology. A prospective study with clinical and independent radiologic follow-up. Spine (Phila Pa 1976). 1992;17(10):12051212. 